\title{
El tratamiento documental del mensaje audiovisual
}

\author{
Blanca Rodríguez Bravo
}

\section{RESUMEN}

Se analizan las peculiaridades del documento audiovisual y el tratamiento documental que sufre en las emisoras de televisión. Observando a las particularidades de la imagen que condicionan su análisis y recuperación, se establecen las etapas y procedimientos para representar el mensaje audiovisual con vistas a su reutilización. Por último se realizan algunas consideraciones acerca del procesamiento automático del video y de los cambios introducidos por la televisión digital.

Palabras clave: Análisis de contenido; Análisis documental; Centros de documentación; Documentos audiovisuales; Emisoras de televisión; Mensaje audiovisual; Procesamiento automático; Recuperación de la información; Representación de la información; Servicios de documentación de televisión; Tratamiento documental; Televisión di-
Artículo recibido:

10 de noviembre de 2004

Artículo aceptado:

7 de diciembre de 2004 


\begin{abstract}
Documentary treatment of the audio-visual message Blanca Rodríguez-Bravo

Peculiarities of the audio-visual document and the treatment it undergoes in TV broadcasting stations are analyzed. The particular features of images condition their analysis and recovery; this paper establishes stages and proceedings for the representation of audio-visual messages with a view to their re-usability Also, some considerations about the automatic processing of the video and the changes introduced by digital TV are made.
\end{abstract}

Keywords: Audiovisual materials; Audiovisual message; Automatic processing; Content analysis; Digital TV; Indexing; Information representation; Information retrieval; Information units; Knowledge organization; Video.

\title{
I. El DOCUMENTO AUDIOVISUAL: CONCEPTO, CARACTERÍSTICAS Y TIPOS
}

$\mathrm{U}$ n documento audiovisual es aquel que en un mismo soporte contiene imágenes en movimiento -información visual-y sonido, sin distinción del soporte físico ni de la forma de grabación, y que requiere un dispositivo tecnológico para su grabación, transmisión, percepción y comprensión. Se caracteriza pues por su dualidad o carácter mixto, su diacronía que le viene dada por el canal audio, y su opacidad que lo hace ser dependiente de la tecnología para tener acceso a su contenido.

Los documentos de imagen única, estática, construyen sus mensajes sobre una trama exclusivamente espacial, estable en el tiempo, que sólo utiliza el código icónico y el canal visual. La primera liberación de la imagen estática se consigue mediante la superposición de varias secuencias y la consiguiente obtención de imágenes en movimiento. Éste es el ingrediente básico de los documentos audiovisuales entre los que destacan los productos cinematográficos y televisivos (Pinto, García y Agustín, 2002:192).

El análisis de contenido de los documentos audiovisuales es complejo debido a la ya citada yuxtaposición de códigos pero también a la diversidad de documentos de los que se ocupa: géneros cinematográficos, videográficos y televisivos. Entre estos materiales se encuentran documentos con contenidos pedagógicos, científicos, técnicos o de divulgación, así como los generados por medios de comunicación de masas de temática más relacionada con la 
actualidad y la creación. Se ha generado una cultura audiovisual que hace evidente que la historia del siglo XX no se pueda estudiar seriamente si no se les concede la misma importancia a las fuentes audiovisuales que a las escritas.

En los archivos audiovisuales se pueden encontrar diferentes tipos de soportes; sin embargo hasta el momento los más comunes son la película cinematográfica y el video. El cine como patrimonio audiovisual que hasta la aparición y popularización del video era el medio audiovisual por antonomasia, se ha conservado y tratado tradicionalmente en las filmotecas o cinematecas, organismos dedicados al archivo, exposición, preservación y difusión de la obra cinematográfica, así como a la conservación de técnicas y tipos de filmación en desuso.

El video supuso, desde su difusión comercial en los años setenta, la síntesis de las tecnologías precedentes - película, disco y fotografía- y facilitó la grabación, la conservación y la reproducción del sonido juntamente con la conservación y reproducción de la imagen. La popularidad adquirida hace que se encuentre en diversas instituciones que le proporcionan un tratamiento similar aunque adaptado a sus necesidades particulares.

Frente al discurso textual y al documento visual fijo, los medios que descansan en la imagen móvil y en el sonido plantean problemas en su proceso de análisis debido al carácter móvil y transitorio de los mensajes que emiten. El documentalista se verá obligado a volver a ver o volver a escuchar y las secuencias se definirán y localizarán mediante cronómetro. Por otra parte, los documentos audiovisuales representan la síntesis de la interrelación entre la imagen y la palabra, pues se apoyan mutuamente para resolver las carencias que cada subsistema tiene por sí solo. Así como la fotografía necesita el texto del pie de foto para centrar el significado de la imagen, aquí es el sonido el que realiza esa necesaria función contextualizadora. Además, la superposición secuencial de imágenes ayuda también a explicar los mensajes. Los documentos audiovisuales resultan más precisos semánticamente que los visuales y más completos semánticamente que los sonoros.

Dado que la información audiovisual está integrada por elementos que pertenecen al ámbito de las imágenes y del sonido, su estudio debe abordarse desde una doble dimensión:

- considerando cada uno de los niveles separadamente,

- considerando los dos niveles conjuntamente, y observando las transformaciones que éstos experimentan como resultado de la combinación de códigos.

Asimismo será preciso considerar las finalidades del tratamiento de estos documentos, que pueden ser dos: 
- Recuperación unitaria de videos, DVDs, etcétera, en bibliotecas y otras unidades de información.

- Recuperación fraccionada en microunidades informativas (secuencias, escenas, planos, etcétera) de noticias, reportajes, spots publicitarios, etcétera, en medios de comunicación.

Esta realidad implica que la unidad documental podrá ser cualquier unidad temática de información (película, video o programa, reportaje, secuencia o plano).

Si tratamos con documentos audiovisuales que forman parte de bibliotecas se describirán como el resto de la colección, bien de forma unitaria o bien de manera analítica pero se les aplicarán, generalmente, las mismas normas: las ISBD (NBM), el capítulo correspondiente de las reglas de catalogación españolas, la misma lista de encabezamientos de materia y la CDU.

Si se trata de los videos conservados en los archivos/servicios de documentación audiovisual de televisión, la unidad de tratamiento será la secuencia o el plano. Es este caso el que vamos a abordar seguidamente.

\section{El tratamiento documental del mensaje audiovisual}

Los servicios de documentación de los medios audiovisuales han de constituir sistemas de gestión documental que faciliten la explotación de los fondos conservados. Habrán de responder a una tipología muy variada de demandas y sus documentos habrán de ser localizados en un tiempo mínimo para atender las necesidades de una emisión continua de informativos y programas en directo.

El sistema documental es la piedra angular de todo sistema de archivos audiovisuales. No tiene ninguna utilidad para una organización acumular miles de cintas de video, si no se está en condiciones de recuperar su contenido. Todos los documentos conservados deberán ser objeto de un análisis más o menos detallado, ya que si se ha considerado que había que conservarlos es porque pueden ser susceptibles de ser explotados.

Para poder conseguir este objetivo es fundamental establecer un modelo de análisis documental que tenga en cuenta la necesidad de una explotación eficaz y diversificada del fondo conservado, y definir un sistema de gestión de bases de datos (SGBD) adaptado a las necesidades específicas del medio.

El objetivo del análisis documental es obtener una representación del documento audiovisual que pueda ser almacenada y recuperada por el sistema, dicha representación todavía en la actualidad es mayoritariamente textual y debe de cumplir con tres funciones básicas, las dos primeras comunes a todo tipo de documentos y una tercera, específica de los documentos audiovisuales: 
- proporcionar un conjunto de datos que identifiquen inequívocamente el documento,

- proporcionar una representación de su contenido semántico y

- proporcionar una representación de las imágenes y/o sonidos que contenga el documento.

Cada emisora de televisión ha establecido los campos de información que constituyen sus bases de datos en función de sus necesidades específicas. FIAT/IFTA estableció en 1992 el Minimum Data List, una lista de 22 campos que es un buen punto de partida para definir un sistema de descripción de los materiales de televisión. Los campos se agrupan en tres áreas: área de identificación, área técnica y área de derechos.

Parte de estas informaciones son datos ya disponibles desde la creación o producción del documento, antes de su entrada en el archivo. Es fundamental que la base de datos que gestiona el archivo esté relacionada con las bases de datos de producción y emisión, de tal manera que la información fluya fácilmente de un entorno a otro. Así, el servicio de documentación podrá centrar la tarea del documentalista en la parte del análisis documental que le confiere más valor añadido: el análisis de contenido.

Los documentos audiovisuales están constituidos por imágenes y sonidos, y organizados en un conjunto coherente que constituye la obra audiovisual. Esta obra comprende una o diversas secuencias, cada una de las cuales está compuesta por diversos planos o planos-secuencia. Lo que es relevante, desde el punto de vista del análisis documental, es que esta obra audiovisual debe poder ser recuperada por el usuario de un archivo de televisión en dos niveles: como un todo o como una parte, la obra como tal o un extracto de ella, una imagen concreta de la obra.

La unidad documental podrá ser cualquier unidad temática de información susceptible de ser indizada por sí misma (reportaje, secuencia o plano), forme parte o no de un conjunto más amplio. A su vez, este conjunto (programa), puede ser también considerado como otra unidad documental. Como señala F. del Valle (2002:475) el Análisis Documental precisa segmentar el video jerárquicamente en segmentos, secuencias y planos. Un plano es una toma continua de cámara. Una secuencia está compuesta por uno o más planos que presentan diferentes tomas del mismo acontecimiento con una relación espacial y temporal. Un segmento está compuesto por una o más secuencias relacionadas.

Para hacer una buena gestión de recursos es preciso establecer el nivel de análisis necesario para cada tipo de documento. El nivel de análisis estará en relación con la explotación posterior que este material pueda tener. Los contenidos de los materiales con un alto potencial de ser reutilizados, exigirán 
una descripción y representación más detallada que facilite su recuperación por cualquier concepto. Éste sería el caso de los programas informativos y documentales y de los originales de rodaje.

En el caso de un telediario o de un programa informativo que contenga diversos reportajes se habrá de analizar como unidad independiente cada una de las noticias o reportajes, como se haría con los artículos de un periódico o revista (analíticas).

El análisis conceptual o semántico del reportaje puede ser similar al análisis de un documento textual. Si comparamos el análisis documental de una misma noticia publicada en un periódico y el de un reportaje emitido en un informativo de televisión, encontraremos unos elementos de descripción muy similares: título, resumen, indización por palabras clave, etcétera. Sin embargo, como documento audiovisual puede ser analizado en un segundo nivel, si se describen e indizan las imágenes concretas que contiene, que pueden o no estar directamente relacionadas con el tema global del documento. La dificultad de analizar documentos audiovisuales estriba en tener que diferenciar el tema del documento o reportaje, normalmente genérico y que viene dado por el discurso oral de la información, para ilustrar el cual aportan los distintos planos visuales, siempre concretos, de lugares, objetos, sujetos y acciones.

Como expone Hernández Pérez (1992:204-296) entre imagen y sonido se establecen diferentes relaciones que influyen en el proceso de percepción de los mensajes:

- Relación redundante: sonido e imagen transmiten la misma información. En ese caso debe detallarse la información visual fundamentalmente.

- Relación relevante: la información del sonido y la imagen son complementarias. Deben detallarse las dos.

- Relación irrelevante: la imagen proporciona un aspecto de la información y el sonido otro. Deben reseñarse las dos.

- Relación contradictoria: imagen y sonido proporcionan una información distinta aparentemente, aunque siempre guardan una mínima conexión. Se describen las dos.

Las relaciones entre el discurso verbal y el icónico puede considerarse desde otros puntos de vista además del expuesto por Hernández que se refiere a la coherencia o distorsión semántica entre "lo que se dice" y "lo que se ve". La imagen es coherente respecto al texto cuando confirma su contenido y es distorsionante o contradictoria cuando su contenido modifica la información oral.

La consistencia entre el discurso icónico y el verbal propicia una máxima inteligibilidad de la información puesto que ambos lenguajes actúan 
complementándose. La falta de coherencia debilita la comprensión al obligar al espectador a un sobreesfuerzo estéril.

Agirreazaldegi (1997:168-169) establece otras dos relaciones, la de sincronía/asincronía y la de autonomía/dependencia. La primera representa el grado de simultaneidad entre los contenidos manifiestos del sonido y la imagen. Hay sincronía cuando se ve lo mismo que se dice en el momento en que se dice, y asincronía cuando las imágenes se muestran con un desplazamiento temporal de varios segundos con respecto al texto al que van referidas. Por lo que se refiere a la segunda relación, una imagen dependiente es aquella que no puede explicarse por sí misma ni remitir al tema del acontecimiento o al sentido de éste, ya que encuentra su sentido en el texto, necesita el anclaje verbal. Son imágenes autónomas las que no tienen o no necesitan un texto de anclaje para gozar de significatividad, o aportan información nueva o de interpretación unívoca.

Como pone de relieve Teresa Aguirreazaldegi (1997:564-565) la documentación audiovisual cumple tres funciones en la información televisiva:

- una función propiamente informativa, cuando contextualiza la información y los documentos aportan su valor testimonial y evocador;

- una función completiva, en noticias que tienen vacíos informativos;

- una función ilustrativa o simbólica, para ilustrar temas abstractos o que carecen de imágenes propias, como para apoyar el texto sonoro o la información gráfica.

La función informativa es la función propia de la documentación audiovisual que le aporta su valor testimonial y evocador. Existiría en este caso una relación de coherencia entre la banda imagen y la banda sonido, y una autonomía de la imagen. En cambio la utilización de la documentación audiovisual con funciones completivas o ilustrativas responde a razones de disponibilidad de las grabaciones y de rentabilidad económica. Los redactores se ven a menudo limitados para ilustrar sus programas informativos y han de recurrir a las imágenes de archivo, lo que implica a menudo relaciones irrelevantes e incluso contradictorias entre imagen y sonido, o relaciones de dependencia y distorsión.

2.1. El análisis documental del documento audiovisual: etapas y procedimientos

Las fases del análisis de contenido de los documentos audiovisuales han sido establecidas por varios autores; es el caso de Fournial (1986:249-258), Cunha (:15-30), Hernández Pérez (1992), López de Quintana (2000:83-181) 
e Hidalgo Goyanes (1999:333-350), entre otros, en un sentido básicamente coincidente con las que presenta la obra que dirige Bellveser (1999:78):

1. Elementos de identificación

2. Análisis del contenido (Visionado):

- Lectura de la banda de imagen

- Lectura de la banda de sonido

3. Resumen

4. Indización

Recientemente Pinto, García y Agustín (2002:265) establecen, asimismo, las siguientes etapas:

- Visionado: implica el conocimiento de los rasgos específicos del lenguaje audiovisual.

- Determinación de la estructura del contenido y descripción documental: supone el conocimiento de los diferentes géneros audiovisuales y sus respectivas pragmáticas.

- Documentación exógena, interpretación y contextualización documental: se buscan apoyos documentales para interpretar el documento objeto de análisis.

- Síntesis de todas las fases previas.

- Representación del contenido documental: elaboración de los diferentes productos documentales.

La descripción de las imágenes sólo puede hacerse a partir de un visionado completo del documento. La diacronía y opacidad del documento audiovisual obligan a ello como obliga el documento sonoro. Para facilitar la localización de las imágenes es necesario indicar el punto temporal del documento (Time Code o código de tiempo) en el que se localiza cada plano o secuencia. Durante el visionado el documentalista debe "leer" las imágenes y crear una descripción textual, traduciendo en palabras el contenido visual y sonoro del documento, de forma lo más objetiva posible, y teniendo presente tanto el aspecto formal como el del contenido. Se trata no sólo de ordenar aquello que el ojo percibe en muy pocos segundos sino de identificar los elementos, para lo que es necesario poseer los referentes adecuados. Las competencias establecidas por Vilches (1987) son: competencia iconográfica, narrativa, estética, enciclopédica y lingüístico-comunicativa.

El nivel de detalle de la descripción dependerá del tipo de documento y del tipo de búsquedas que posteriormente puedan establecerse. Fijar el nivel de descripción de las imágenes es fundamental para una buena gestión del 
sistema. Una descripción demasiado detallada que pretenda describir todos los objetos y acciones reconocibles en cada plano es muy costosa en dedicación para el analista y puede producir un exceso de ruido en la búsqueda. En el otro extremo, una descripción demasiado somera o selectiva, provocará silencio. Una descripción media tiene que incluir como mínimo la descripción de las secuencias más relevantes, indicar los nombres de los personajes, identificar los lugares y describir las acciones que se desarrollan.

Conviene considerar las peculiaridades de la imagen; es decir, su carácter sintético y polisémico que implican su rápida selección en la recuperación y flexibilidad en su utilización. Estas características derivan de su código icónico, menos formalizado que el verbal. La descripción de la imagen es intrínsecamente subjetiva en virtud de la separación entre lo que ésta denota -el significado común del signo- y lo que connota -el significado cultural del signo-, y requiere con frecuencia del texto o el sonido para fijar su significado, para su contextualización.

La traducción de la información de un código icónico a otro verbal no está, en absoluto, exenta de dificultades. Hay que ser capaz de mostrar con palabras una realidad teniendo en cuenta las necesidades del usuario. La representación textual de las imágenes supone distorsiones al no tratarse de imágenes de conceptos sino de realidades, lo que obliga a reconocer esos entes y a denominarlos. Es preciso recordar que aunque los planos están sujetos a grandes divergencias interpretativas conviene describirlos fundamentalmente con los conceptos concretos que existen referencialmente en ellos. El documentalista acostumbrado a analizar documentos escritos tiende, invariablemente, a analizar imágenes a través de términos abstractos, sin considerar que una imagen rara vez significa de forma unívoca un término abstracto y ello limita la reutilización de la imagen al fijar una lectura en detrimento de innumerables otras.

Resulta necesario, igualmente, conocer sobre planos, encuadres, efectos de iluminación, movimientos de cámaras, etcétera. Es conveniente que el analista conozca no sólo estas cuestiones fotográficas y/o cinematográficas sino también las etapas de producción de la noticia informativa, lo que le permitirá identificar las características de los productos audiovisuales televisivos. Reseñable resulta, pues, la trascendencia que en la descripción presentan los aspectos compositivos y técnicos tan relevantes como los semánticos al momento de la recuperación. La descripción de las imágenes debe incluir su descripción formal.

Por lo que se refiere a los tipos de encuadres, éstos suelen estar muy limitados en los formatos televisivos, el encuadre horizontal es el más usual y está prácticamente estandarizado en las cadenas televisivas. Cuenta con el formato no sólo de los grabadores de imágenes sino con el de los reproductores. Con 
respecto al ángulo, el medio es el más normal en televisión y quizá se debe a la tendencia al periodismo de declaraciones y la moda cada vez más extendida de la captación de imágenes con cámara al hombro, lo que provoca tener a los diferentes personajes prácticamente de frente al objetivo y dar la apariencia de cercanía respecto al personaje. Igualmente suelen verse ángulos picados prácticamente imperceptibles al ser tomados con trípodes. Este ángulo se percibe al captar un hecho noticioso que ha obligado al reportero a levantar la cámara, o para dar una perspectiva de conjunto en situaciones donde existe un gran número de actores en la información. Por último la utilización del ángulo cenital suele ser habitual en retransmisiones deportivas en recintos cerrados (balonmano, baloncesto, etcétera) donde puede colocarse una cámara perpendicular a objetos concretos (porterias, aros, etcétera) lo cual le permite al realizador la posibilidad de ofrecer imágenes y repeticiones muy poco habituales y espectaculares de los acontecimientos deportivos.

Con respecto a los diferentes planos el más televisivo de todos es el Plano Medio (PM), la razón la encontramos en que el periodismo televisivo, tal y como se entiende en la actualidad, es un periodismo de declaraciones donde éstas son el eje fundamental de cualquier programa informativo. Tan es así que en muchas ocasiones el resto de las imágenes son únicamente relleno de la información. En la descripción de planos algunas cadenas no indican este tipo de plano por estimar que como son lo habitual describirlas resultaría redundante.

Uno de los planos más cinematográficos es el Plano Americano (PA) creado por la industria cinematográfica para un género concreto, el western, por la necesidad de captar desde la cabeza del personaje hasta el fin de la cartuchera. En informativos este plano es inusual pero sí se encuentra en programas de entretenimiento (concursos, magazines, ${ }^{*}$ etcétera.). Junto a ellos se utiliza también el Plano General (PG) que es válido tanto para personajes y conjuntos de personas como para edificios, planos abiertos, etcétera. Como se ha señalado resulta prácticamente imposible identificar clara y plenamente cada uno de los íconos representados en las imágenes, por lo que existe una selección en la que se determina cuál es el elemento principal de la imagen y será de este protagonista de quien tengamos la determinación del plano, independientemente de su naturaleza u origen (persona, animal o cosa).

Los elementos básicos de identificación y representación de los documentos audiovisuales conservados en los archivos de televisión son:

1. Datos de identificación o elementos de catalogación:

- Títulos.

* Magacín: espacio de televisión en el que se tratan muchos temas inconexos y mezclados”. Dic. de la RAE. Lo que para nosotros sería un noticiario. Nota del corrector. 
- Menciones de responsabilidad (créditos).

- Datos de producción (productora, distribuidora, fecha de producción).

- Datos de emisión (fechas de emisión, cadena, ámbito de difusión).

- Duración.

- Número de producción, número de archivo.

2. Análisis de contenido:

- Tipificación del tipo de documento (género, forma).

- Resumen conceptual o temático.

- Descripción de imágenes y/o sonidos.

- Clasificación y/o indización.

3. Descripción técnica y relación de soportes:

- Características técnicas: formato, tipo de soporte.

- Referencia/s o signatura/s de localización en el archivo del/de los soporte/s que contienen el documento.

4. Datos relativos a las condiciones de uso:

- Identificación de los derechos (copyright) de que dispone el archivo sobre el documento.

El análisis queda plasmado en la base de datos en una serie de campos que son campos onomásticos, campos geográficos, campos temáticos, campos cronológicos, campos de localización, campos de control y campo de contenido.

Campos onomásticos: son aquellos referidos a las personas físicas y jurídicas referenciadas en las imágenes y que aparecen en ello. Es decir, diferencian entre lo que se ve y de aquel o aquellos de quienes se habla. Mientras el primer campo señalado nos muestra sobre qué personaje se desarrolla el tema, en el segundo se señalan los personajes cuyas imágenes se podrán reutilizar en el futuro. Al hablar de personas nos referimos tanto a las físicas cuanto a las jurídicas o morales (Onu, Unesco, etcétera) y respecto a las físicas ya sean las reales o representadas por un actor o actriz (en este último caso se añade el calificador /F/).

Otros campos onomásticos son aquellos en los que se indica la realización, la producción y el cuadro técnico que han producido la noticia, así como la dirección e interpretación de piezas artísticas que son vistas o referenciadas en el producto televisivo o en los brutos de rodaje.

Las reglas para elaborar puntos de acceso de personas son efectuadas por cada departamento de documentación y creadas ad hoc una vez analizadas las necesidades propias del servicio. Televisión Española (TVE) es el modelo a seguir por parte de otras televisiones estatales y autonómicas de España, y ella adapta las reglas de catalogación a las necesidades del servicio 
de documentación audiovisual, a partir de identificar a estos personajes por su nombre más conocido.

Campos geográficos: los campos geográficos repetidos en las diferentes bases de datos de las empresas televisivas no son tan universales como los anteriores. Todas estas bases de datos cuentan con un campo en el que se muestran las zonas geográficas o países sobre los que influye un acontecimiento o noticia.

Otro campo geográfico nos ubica la noticia en una localidad o país en el caso de desconocer la ciudad. Aquí se señala el lugar donde se produce la noticia aunque no se muestren imágenes de él.

Existe por último un campo que nos indica la localidad de la que se nos muestran recursos visuales que pueden ser reutilizados para futuras noticias. Si es posible se indicará la localidad, la descripción de la imagen y los efectos atmosféricos destacables.

El control de los nombres geográficos ha tenido como punto de partida el tesauro de topónimos del Centro de Información y Documentación Científica (CINDOC) pero ha sido adaptado por los Servicios de Documentación.

Campos temáticos: al igual que en los campos onomásticos y geográficos existe una distinción clara entre lo que se ve y aquello a lo que se hace referencia; en los campos temáticos se utiliza la misma filosofía y se cuenta siempre con un campo tema y otro plano tema.

En el campo tema se indicará la temática de la noticia con independencia de las imágenes; es decir, se analiza la banda de sonido teniendo en cuenta la locución, el sonido ambiente, las declaraciones, etcétera.

Por el contrario, el campo plano tema olvida el sonido y centra su representación en la banda de imagen. En los campos de descripción temática audiovisual se plasma plano a plano la semántica de las imágenes contenidas en la noticia, ya que una noticia televisiva está organizada por fragmentos de imágenes que no siempre tienen una relación temática entre ellas, al igual que tampoco ha de existir obligatoriamente relación con la banda de sonido.

Existe en algunas bases de datos, como la de Antena 3 TV, un campo denominado identificador que sirve para aglutinar noticias generadas a partir de un mismo hecho o un mismo personaje, etcétera. Su utilización permitiría recuperar todos los documentos relacionados directa o indirectamente con esta temática.

Entre los campos temáticos se pueden mencionar el campo de título y el campo de género. El título es propuesto, si el producto no posee ya uno, por el propio analista una vez visto el documento audiovisual y descifrada su temática. Debe ser claro, conciso y preciso.

Con respecto al campo de género, que suele incluir la forma, hay que resaltar que se deben indizar todos los documentos por el género al que pertenezcan y 
por la forma que presenten cuando ésta sea significativa para determinar su contenido. Los descriptores de género reflejan distintos puntos de vista: temático, público al que va destinado o fin del documento.

La forma afecta al cómo del documento pero con frecuencia nos advierte de su importancia (noticia, reportaje, documental, etcétera) y nos ayuda a valorarlo. Por ello, a continuación del género es usual reflejar las formas más habituales: antología, adaptación, debate, entrevista, reportaje, serial, drama, etcétera.

Este campo es relevante porque las demandas de información de los usuarios y sus criterios para aceptar los resultados de la búsqueda no se basan únicamente en los conceptos representados en el documento, el cómo se representan resulta, asimismo, decisivo a la hora de la elección. El cómo de la banda de sonido se refleja en este campo y el de la banda de imagen en los campos de planos de personas, temas, lugares y en el de contenido.

Las herramientas documentales existentes para plasmar dicha información en la base de datos son listas de encabezamientos de materia y tesauros de diferentes temáticas que es preciso adaptar al servicio, dado que estos instrumentos han sido concebidos para tratar documentos textuales y se adaptan mal a la descripción de las imágenes que requieren descriptores concretos. Resultan también útiles las escasas herramientas terminológicas existentes concebidas para la descripción de imágenes.

Campos cronológicos: se repiten una serie de campos con este contenido. El primero es el campo en que se especifica la fecha en que se ha producido la noticia. Un segundo mostrará la fecha de emisión de dichas imágenes, ya que no tienen por qué coincidir. Además de la primera fecha de emisión pueden reflejarse las reemisiones sucesivas.

Campos de localización y características técnicas: existe una serie de campos que nos indican la localización física de la cinta en el fondo documental del archivo al igual que la ubicación de las imágenes dentro de la cinta.

Otros campos muestran características técnicas del video: soporte, formato, existencia de insertos en blanco y negro, existencia de sonido natural, etcétera. Es interesante igualmente el campo de duración que permite conocer el tiempo real de la información contenida en el soporte.

Campo de contenido: Este campo presenta el análisis cronológico, la descripción de la imagen y el sonido que conforman la obra audiovisual, y fragmenta dicha información por medio de las secuencias o conjuntos de secuencias con idéntica temática. Permite describir secuencialmente los planos, ejercer el reconocimiento de personas, lugares y temas de especial dificultad, y estará condicionado por la experiencia y los conocimientos del analista.

El análisis del contenido será la exposición completa o resumida, según el tipo de documento, en lenguaje natural, del tema o temas objeto del documento 
así como del tratamiento o presentación formal de tales temas. Para facilitar su recuperación, el texto se estructura en frases y párrafos que estén en consonancia con la estructura sintáctica del sistema informático. En cuanto a las frases, se les exige sencillez y brevedad ya que la posibilidad de relación entre dos términos está siempre en razón inversa a la longitud de la frase a la que pertenecen.

El análisis del contenido tiene en cuenta un doble punto de vista: el material y el formal. El análisis del contenido material del documento responde al qué en su sentido más amplio; esto es, a las materias tratadas ya se refieran a personas, lugares, temas o fechas determinadas.

Para las personas, sujetos u objeto de la acción, se valoran, especialmente, elementos identificativos tales como edad, raza, nacionalidad, sexo, situación social, etcétera que sirvan para contextualizar fielmente cada situación. Igualmente, se precisa el tiempo de la acción (siglo, décadas, año, estación, día, noche, pasado, futuro, etcétera). En resumen, la descripción refleja el sujeto y objeto de la acción (quién, qué), la acción misma narrada en gerundio, el lugar de la acción (dónde), su tiempo (cuándo), la causa (por qué), el fin (para qué), la forma (cómo) y los medios (mediante qué). En suma, en este campo se establecerá el código de tiempo, se señalará el tipo de plano y/o movimiento de cámara y se describirá la acción.

Otros campos repetidos: un campo muy común es el del control del analista, cuya finalidad es realizar un seguimiento de la producción, selección y borrados realizados por cada uno de los trabajadores del servicio. De extremo interés es el campo que especifica los derechos a los que está sujeta la información contenida en el video. Se indicará quién detenta los derechos y cuáles son éstos: reutilización, alcance, explotación y venta.

Se repite también el campo de notas cuyo uso es el habitual en la descripción de otros tipos documentales. Este campo permite completar la descripción del documento con informaciones sobre el título, la producción, emisión, etcétera de menor relevancia, pero necesarias para permitir una mejor identificación del documento o la recuperación de la información contenida en él.

Como se ha podido apreciar algunos campos sirven para describir formalmente el documento y otros están destinados a formalizar el análisis de contenido.

\subsection{Clases de análisis}

Análisis resumido o argumental: se utiliza para documentos dramáticos, argumentales o de ficción y, excepcionalmente, en documentos informativos que no hayan sido vistos o que por sus características no requieran un análisis secuencial completo. 
En estos documentos la descripción del contenido se hará en forma de resumen, con el tema y argumento del documento o, cuando éste no sea de ficción, se describirán de forma sucinta las distintas partes o elementos de modo que formen un todo único, coherente y representativo del contenido.

Análisis secuencial cronológico: se tiene en cuenta este análisis en documentos de carácter informativo o documental que están formados por una pluralidad de secuencias o unidades documentales significativas. Es éste el análisis más completo y requiere una visión previa completa y detallada del documento, la contrastación de los datos contenidos en la información que aportan la imagen y el sonido y, de ser posible, conocimientos previos sobre la temática principal del documento.

La descripción secuencial tiene especialmente en cuenta los contenidos temáticos, generales o parciales y las informaciones sonoras o visuales independientes cuya recuperación pueda ser relevante. El análisis secuencial alcanza su máximo nivel de eficacia y precisión cuando se realiza cronológicamente; esto es, con mención del minuto y segundos en el que aparecen las distintas secuencias.

Análisis secuencial-temático: Las especiales características de algunos programas de televisión obligan, en ocasiones, a establecer un análisis cronológico no lineal y no secuencial puro sino agrupado. Este tipo de análisis se utiliza en aquellos programas en los que las materias que los componen aparecen fragmentadas a lo largo de su contenido pero son susceptibles de agruparse por temas (por ejemplo programas con base en entrevistas y actuaciones). En estos casos los contenidos se estructuran temáticamente incluyendo la minutación que corresponda a cada bloque o tema y su duración.

Análisis factual: aplicado especialmente a los documentos de contenido deportivo, los cuales por su estructura no permiten una descripción puramente secuencial sino que, a la vez, exigen un tratamiento que facilite el máximo nivel de recuperación de contenidos fácticos (tipo de prueba, equipos, resultados, jugadas, incidencias, curiosidades, etcétera).

Por último conviene no obviar que el análisis de los contenidos temáticos se completa con el análisis formal y se consideran los sujetos, esto es, la persona o personas que intervienen en el programa tales como presentadores, moderadores, público presente o participante, etcétera, el lugar o lugares de grabación o rodaje (estudios, exteriores, etcétera) y aspectos significativos de la realización (iluminación, escenografía, animación, decorados, etcétera).

En suma, la representación de las imágenes es una herramienta fundamental para poder reutilizar más eficazmente el material del servicio de documentación de televisión. A partir del resultado de una búsqueda, la lectura de la descripción de imágenes permitirá seleccionar solamente aquellos documentos que sean realmente pertinentes y evitará tener que revisionar 
otro material, lo que redunda en una mejor conservación además de mayor eficacia del servicio.

\section{El procesamiento automático de los documentos audiovisuales y} LAS PERSPECTIVAS DE CAMBIO EN LA TELEVISIÓN DIGITAL

Las empresas de televisión están viviendo la evolución hacia la televisión digital que afecta a toda la cadena de producción, una transformación tanto del soporte de producción, como del de emisión y archivo. En concreto se trata de sustituir las cintas de video por los servidores de video digital. Esta evolución implica no sólo un cambio de formato sino también una transformación en la metodología de trabajo de todos los elementos que participan en la producción de televisión, entre ellos el archivo/servicio de documentación de televisión.

La tecnología digital permite integrar la función de archivo en la cadena de producción y difusión de la televisión. La necesidad de identificar los contenidos se impone desde el momento de su creación y esta identificación es imprescindible para localizar contenidos que son inmateriales. Por tanto asistimos a una revalorización de la función de documentación de los contenidos, que debe realizarse ya desde el mismo momento de su producción. Al mismo tiempo que se digitalizan las imágenes pueden introducirse los datos asociados o metadatos en forma de ficheros que pueden ser transferidos junto con las imágenes; se integraría así la función de documentación en el proceso de producción y no como un añadido al final de la cadena.

Gracias a la digitalización se han podido desarrollar también sistemas de ayuda a las tareas de representación de los productos televisivos, lo que permite ya actualmente mejorar los sistemas de descripción de las imágenes y adjuntarles imágenes fijas extraídas del propio video a las descripciones textuales. Estos sistemas, junto con la facilidad de acceso a las imágenes mismas que implica el uso de video-servidores, permiten replantear los sistemas de gestión documental de los archivos audiovisuales para adaptarlos a las oportunidades y las demandas del nuevo entorno.

Actualmente la mayoría de archivos de televisión están todavía en formato analógico. La digitalización empieza a implantarse en las televisiones y en los sistemas de producción y emisión. Los servicios de documentación y archivo están participando directamente en este proceso de cambio y creando una nueva metodología y nuevas bases de datos que incluyen los datos (las imágenes) y los metadatos (su identificación y descripción). Pero el archivo masivo sigue estando en formatos de cinta analógicos y las bases de datos textuales seguirán siendo utilizadas, puesto que la tecnología no permite hoy 
todavía digitalizar y almacenar en los servidores cantidades masivas de video de calidad profesional, a un costo abordable. No obstante, la tecnología sigue avanzando. Se está trabajando continuamente en la creación de nuevas normas y programas de compresión que reduzcan la cantidad de memoria necesaria para almacenar la señal de video digitalizada. Si se produce también una evolución que permita disponer de memorias más potentes y económicas el cambio total de los archivos de TV puede estar próximo.

Como ponen de relieve Moreiro y Marzal (2001:156) el análisis automático de imágenes en video se encuentra en un proceso de desarrollo y en él se distinguen seis áreas de investigación: reconocimiento automático de imágenes; segmentación temporal de secuencias; análisis de movimiento de cámara; identificación de los valores de encuadre; análisis de sonido, y resumen automático. Por su parte, el grupo de expertos que integran el MPEG (Motion Picture Experts Group) trabaja, desde 1988, en la normalización del campo del audiovisual en formato digital, con la intención de que se establezca una sintaxis única para representar y transmitir la información.

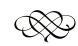

\section{BiBLIOGRAFÍA}

Aguirreazaldegi Berriozabal, T. (1996). El uso de la documentación audiovisual en los programas informativos diarios de televisión. Bilbao: Universidad del País Vasco.

Agustín Lacruz, Ma C. (1999). "Metodología para la indización de documentos no textuales: algunas precisiones a propósito de los documentos gráficos y audiovisuales", en III Encuentro ISKO-Espa$\tilde{n} a$ (pp.145-159). Zaragoza: F. J. García Marco.

Alexander, A., Meehleib, T.(2001). "The Thesaurus for Graphic Materials: its history, use, and future (pp.189-212)", en Roe, S. K. The audiovisual cataloging current. The Haworth Information Press.

Bailaci Puigdellívol, M.(2002). "Documentalista audiovisual, un ofici apassionant”, en Item, 32, 5-16.

Bellveser, E. (ed.). (1999). Manual de documentació audiovisual en ràdio i televisió. Valencia:Universitat de Valencia.

Benito Amat, C., Castillo Blasco, L. (1996). "Factores condicionantes de las operaciones documentales en medios de comunicación", en Revista Española de Documentación Científica, 19, (2).

Caldera Serrano, J. Análisis de las recomendaciones de la FIAT/IFTA sobre los datos de los archivos de televisión. [Disponible en http://www.ucm.es/info/multidoc/multidoc/revista/num8/caldera.html]. Consultado el 5 de octubre de 2004. 
Caldera Serrano, J. (2002). "Criterios básicos de las bases de datos documentales en las empresas televisivas sobre representación del contenido", en Scire, en.-jun., 75-95.

Caldera Serrano, J. (2002). "Incidencia angular y planos en la descripción de imágenes en movimiento para los servicios de documentación de las empresas televisivas”, en Biblios, julio-diciembre, (13).

Caldera Serrano, J. (2002). "Información geográfica en la representación del contenido de los documentos de imagen en movimiento", en Boletín de la Asociación Andaluza de Bibliotecarios, 67, 31-47.

Caldera Serrano, J., Nuño Moral, $M^{a}$ V. (2004). Diseño de una base de datos de imágenes para televisión. Gijón: Trea.

Castillo, D. del, Jiménez Piano, M. y López de Prado, R.(2003). "El sistema de clasificación de la FIAF para documentos no fílmicos de cine y televisión: cuestiones específicas de compatibilidad para la recuperación de información en cinematografía”, en Frías, J. A., Travieso, C. (eds.). Tendencias de investigación en organización del conocimiento. (pp.357-363). Salamanca: Ediciones Universidad de Salamanca.

Cebrian Herreros, M. (1995). Información audiovisual: concepto, técnica, expresión y aplicación. Madrid: Síntesis.

Cebrián Herreros, M. (1998). Información televisiva: mediaciones, contenidos, expresión y programación. Madrid: Síntesis.

Chang, S. F., Smith, J. R. y Meng, J. (1997). "Efficient techniques for feature-based image/video access and manipulation", en Heidorn, P. B. y Sandore, B. (ed.) Digital image access and retrieval: Proceedings of the 1996 Clinic on Library Applications of Data Processing (pp.8699).Urbana-Champaign, Illinois: Illinois University at UrbanaChampaign, Departmant of Library and Information Science.

Codina, L., Palma, $M^{a}$ V. Web y cine: análisis comparativo de dos bases de datos para la investigación en línea. Formats, n. 3. [Disponible en

http://www.iva.upf.es/formats/formats3/cod_e.htm]. Consultado el 14 de julio de 2004.

Codina, L. Y Palma, Mª V. (2001). Bancos de imágenes y sonido y motores de indización en la WWW, en Revista Española de Documentación Cientifica, 24, (3), 251-274.

Conesa, A. (2000). "Documentación audiovisual en emisoras de televisión”, en Rovira, C. y Codina, Ll. (dir.). Documentación digital 2000. Barcelona: UPF. [Disponible en http://docdigital.upf.es]. Consultado el 10 de mayo de 2004.

Conesa, A. (1995). "La documentación en los medios de comunicación audiovisual”, en Fuentes i Pujol, $\mathrm{M}^{\mathrm{a}} \mathrm{E}$ (ed.). Manual de documentación periodística (pp.147-159). Madrid: Síntesis.

Cunha, I. F. (1987). "Análise documentaría", en Grupo TEMmA. Análise documentária: a análise da sintese (pp.39-62). Coord. De J. W. Smit. Brasilia: IBICT.

Cunha, I. F. (coord.). (1989). Análise documentária: consideraçoes teóricas e experimentaçoes. Sao Paulo: Febab. 
Edmonson, R. Filosofía de los archivos audiovisuales. [Disponible en http://www.unesco.org/webworld/publications/philos/philos. htm.]. Consultado el 4 de septiembre de 2004.

FIAT/IFTA. (1986). Panorama de los archivos audiovisuales: contribución a la puesta al día de las técnicas de archivo internacionales. Madrid: RTVE.

Film researchers handbook: guide to sources in North America, South America, Asia, Australasia, and Africa. (1995). London: Routledge.

Footage: the worldwide moving image sourcebook.(1997). New York: Second Line Search.

Fournial, C. (1986). "Análisis documental de imágenes en movimiento", en FIAT/IFTA. Panorama de los archivos audiovisuales: contribución a la puesta al día de las técnicas de archivo internacionales. (pp. 249-258). Madrid: RTVE.

Galdón, G. (coord.).(2002). Teoría y práctica de la documentación informativa. Barcelona: Ariel.

Garnier, F.(1984). Thesaurus iconographique. Système descriptif des representations. Paris: C.N.R.S.

Greenberg, J. (2002). "A quantitative categorical analysis of metadata elements in image applicable metadata schemas", en Journal of American Society for Information Science, 52, (11), 917-925.

Harrison, H. P. (ed. y comp.). Audiovisual Archives: a practical reader. [Disponible en http://www.Unesco.org/webworld/audiovis/reader/preface. htm]. Consultado el 19 de junio de 2004.

Hernández Pérez, A. (1992). Documentación Audiovisual: metodología para el análisis documental de la información periodística audiovisual. Madrid: Universidad Complutense de Madrid.

Hidalgo Goyanes, P.(1999). "Análisis documental de audiovisuales", en García Gutiérrez, A. (ed.). Introducción a la Documentación Informativa y Periodística (pp. 333-350). Alcalá de Guadaira, Sevilla: $\mathrm{Mad}$

Hidalgo Goyanes, P. (1999). "Documentación audiovisual”, en García Gutiérrez, A. (ed.). Introducción a la Documentación Informativa y Periodística (pp.473-485). Alcalá de Guadaira, Sevilla: Mad.

Hsieh-Yee, I. (2002). Cómo organizar recursos electrónicos y audiovisuales para su acceso: guía para la catalogación. Buenos Aires: GREBYD.

Intner, S. S., Studwell, W. E.(1992). Subject access to films and videos. Lake Crystal, Minnesota: Soldier Creek Press.

López de Quintana, E. (2000). "Documentación en Televisión”, en Moreiro, J. A. (coord.). Manual de documentación informativa (pp. 83-181). Madrid: Cátedra.

López de Quintana, E. (1997/1998). "La explotación comercial de los archivos audiovisuales", en Cuadernos de Documentación Multimedia, 6-7, 305-318.

López Yepes, A. (1993). La documentación multimedia: el tratamiento automatizado de la información periodística, audiovisual y publicitaria. Salamanca: Universidad Pontificia. 
Maillet, L. (1991). Subject control of film and video: a comparison of three methods. Chicago: American Library Association.

MAP.(1995). Film and television collections in Europe: the MAP-TV Guide. London: Blueprint.

Martín Muñoz, J., López Pavillard, J. (1995). "La documentación audiovisual en RTVE", en Documentación de las Ciencias de la Información, 18.

Els materials àudiovisuals a les biblioteques $i$ centres de documentació (1992). València: Generalitat de València.

Maybury, M. T. (ed.) (1997). Intelligent Multimedia Information Retrieval. Menlo park CA: AAAAI Press.

Moreiro González, J. A.(1994). "Análisis de imágenes: un enfoque complementario", en Pinto Molina, M. (ed.). Catalogación de documentos: teoría y práctica.(pp.305-328). Madrid: Síntesis.

Moreiro González, J. A., Marzal García-Quismondo, M. A. (2001). "Modelos teóricos y elementos funcionales para el análisis de contenido documental: definición y tendencias”, en Investigación Bibliotecológica, 15, (31), 125-162.

Moulds, M. (1992). Classification scheme for literature on film and television. London: Aslib.

Moulis, A. M.(1999). "L'analyse documentaire des images animées", en Documentaliste-Sciences de l'information, 36, (3), 171-178.

Nubila, B.D., Gagliardi, I., Macchi, D., Milanesi, L. Padula, M. y Pagani, R.(1994) "Concept-based indexing and retrieval of multimedia documents", en Journal of Information Science, 20, (3), 185 196.

Olson, N. B. (1998). Cataloging of audiovisual materials and other special materials: a manual based on AACR2. 4th ed. Illinois: Minnesota Scholarly Press.

Pinto Molina, M., García Marco, F. J. y Agustín Lacruz, Mª C. (2002). Indización y resumen de documentos digitales y multimedia: técnicas y procedimientos. Gijón: Trea.

Planas Comerma, Ma D. (1994). Hacia la normalización del análisis documental de los materiales audiovisuales. Madrid: Universidad Complutense de Madrid.

Roe, S. K.(2001). The audiovisual cataloging current. The Haworth Information Press.

Rodríguez Bravo, B., Diez Diez, A. (2003) Los contenidos audiovisuales y multimedia en el curriculum de Biblioteconomía y Documentación de la Universidad de León. Ponencia presentada en la 69th IFLA World Conference 2003. Berlin. 4 de agosto de 2003. [Disponible en http://www.ifla.org/IV/ifla69/papers/001s-Bravo_Diez.pdf].

Rodríguez Bravo, B. (2002). El documento, entre la tradición y la renovación. Gijón: Trea.

Rodríguez Bravo, B. (1996). "La indización de documentos no bibliográficos”, en Accademie e Biblioteche d'Italia. 47, (3), 47-54. 
Smit, J. (1987). "A análise da imagem: un primeiro plano", en Smit, J. (coord.). Análise documentária: a análise da sintese. (pp.99-111). Brasilia: IBICT.

Svenonius, E. (1994). "Access to nonbook materials: the limits of subject indexing for visual and aural languages", en Journal of the American Society for Information Science, 45, (8), 600-606.

Terris, O. (2000). "What you don't see and don't hear': subject indexing moving images", en Multimedia Information and Technology, 26, (1), 59-62.

Turner, J. M. (2001). "L'avenir du traitement plan par plan des images animées", en Bulletin des bibliothéques de France, 46, (5), 48-53.

Turner, J. M. (1994). "Indexing film and video images for storage and retrieval", en Information Services and Use, 14, (3), 225-236.

Turner, J. M. y Roulier, J. F. (1999). "La description d'images fixes et en mouvement par deux groupes linguistiques, anglophone et francophone, au Québec", en Documentation et Bibliothéques, 45, (1), 17-22.

Valle Gastaminza, F. (2002). "Indización y representación de documentos visuales y audiovisuales”, en López Yepes, J. (coord.). Manual de Ciencias de la Documentación (pp. 467-485). Madrid: Pirámide.

Vilches, L.(1987). Teoría de la imagen periodística. Barcelona: Paidós.

Weihs, J. (1991).The integrated library: encouraging access to multimedia materials. Phoenix: Oryx Press.

\section{ReCURSOS WEB}

APTN: Associated Press Television News $<$ http://www.aptn.com>

BBC Footage $<$ http://www.bbcfootage.com/>

Electric Library TV \& radio Transcripts.

Footage. $<$ http://www.elibrary.com>

$<$ http://www.footage.net/>.

LC Thesaurus for Graphic Materials I: Subject Terms (TGM I). $<$ http://lcweb.loc.gov/rr/print/tgm1/>

LC Thesaurus for Graphic Materials II (TGMII). $<$ http://lcweb.loc.gov/rr/print/tgm2/>.

Movies Yahoo $<$ http://movies.yahoo.com/>

NBC.

$<$ http://www.nbcnewsarchives.com/>

Sreening Roomâ de Convera $<$ http://www.convera.com/Products/products_sr.asp $>$

VIR Image Engine. Virage. $<$ http://www.virage.com/products/> 